Background Hypoxic-ischaemic encephalopathy leads to neurologic impairment or even death. Secretoneurin (SN), a neuropeptide with angiogenic and anti-apoptotic properties, provided strong neuroprotection in an adult animal model of cerebral ischaemia.

Aim To evaluate the effect of $\mathrm{SN}$ in established in vivo and in vitro models of neonatal hypoxic-ischaemic brain injury.

Methods Seven day old mice underwent unilateral common carotid artery ligation, followed by exposure to hypoxia (8\% oxygen). Thereafter, mouse pups were randomly injected intraperitoneally with $\mathrm{SN}(0.25 \mu \mathrm{g} / \mathrm{g}$ body weight $)$ or vehicle. As endpoint we determined the histological injury score and the number of caspase- 3 positive cells $24 \mathrm{~h}$ after the insult. Primary cultured hippocampal neurons were treated with oxygen glucose deprivation (OGD) on day 10. Neurons were assigned to the following groups: i) control ii) OGD iii) $\mathrm{OGD}+\mathrm{SN}(1,10$ or 50 $\mu \mathrm{g} / \mathrm{l})$. As primary outcome parameter, cell death was evaluated via real time live confocal imaging using calcein-AM and propidium iodide (PI).

Results SN displayed a non-significant trend to lower mean values of histological injury score compared to control $(n=11-12$, $\mathrm{p}>0.05)$ and significantly reduced the number of cells stained positively for activated caspase-3 $(\mathrm{n}=6, \mathrm{p}<0.05)$. In vitro $\mathrm{SN}$ application on hippocampal neurons $(\mathrm{OGD}+\mathrm{SN})$ significantly reduced the number of dead cells assessed by the $\mathrm{PI} /$ calcein ratio compared with the untreated OGD group $(\mathrm{n}=8, \mathrm{p}<0.05)$.

Conclusion We provide first evidence that $\mathrm{SN}$ is neuroprotective in established in vitro and in vivo models of neonatal hypoxicischaemic brain injury and might therefore be considered a promising therapeutic option.

\section{PO-0398 INVOLVEMENT OF THE CORPUS CALLOSUM AFTER PERINATAL ASPHYXIA DEMONSTRATED USING DIFFUSION WEIGHTED MRI IS RELATED TO NEURODEVELOPMENTAL OUTCOME}

T Alderliesten, Y Khalil, C Koopman-Esseboom, MJNL Benders, IC van Haastert, LS de Vries, F Groenendaal. Department of Neonatology, Wilhelmina Children's Hospital University Medical Center Utrecht, Utrecht, Netherlands

\subsection{6/archdischild-2014-307384.1044}

Background Previous studies in 10-year-old children have shown an association between size of the corpus callosum and neurodevelopmental outcome.

Aim In the present study we examined whether diffusion changes in the corpus callosum shortly after birth are associated with outcome in full-term infants with perinatal asphyxia.

Subjects/methods From 2002 to 2013, 127 full-term infants with perinatal asphyxia were examined using diffusion weighted MRI within 7 days after birth (median 4 days; IQR 2 days). To calculate ADC values, regions of interest were manually selected in the anterior and posterior part of the corpus callosum, and ADC values were related to outcome. Adverse outcome was defined as death $(\mathrm{n}=33)$, cerebral palsy or delayed

\begin{tabular}{llll} 
Abstract PO-0398 Table 1 & \\
\hline & Favourable & CP or delayed development & Died \\
Corpus callosum anterior & $1094 \pm 131$ & $1033 \pm 286$ & $899 \pm 233$ \\
Corpus callosum posterior & $1064 \pm 130$ & $921 \pm 265$ & $812 \pm 225$ \\
\hline
\end{tabular}

development at 18 moths (Griffiths DQ <85): $n=12$. Sixtynine of the infants $(54.3 \%)$ received therapeutic hypothermia. Results ADC values $\left(10^{-6} \mathrm{~mm}^{2} / \mathrm{s}\right)$ showed anterior-to-posterior differences, and values were analysed separately. ADC values are presented in the table.

Differences between groups were significant (ANOVA $\mathrm{p}<$ 0.001).

Conclusions Low ADC values during the first 7 days after birth, in particular of the posterior part of the corpus callosum, are associated with an adverse outcome in asphyxiated term neonates.

\section{PO-0399 NEURODEVELOPMENTAL AND BEHAVIOUR OUTCOME OF PRETERMS (GA}

${ }^{1} \mathrm{~K}$ Gücüyener, ${ }^{1} \mathrm{~S}$ Soysal, ${ }^{2} \mathrm{E}$ Ergenekon, ${ }^{3} \mathrm{~T}$ Bedir, ${ }^{2} \mathrm{E}$ Kazanci, ${ }^{2} \mathrm{H}$ Hirfanoglu, ${ }^{2} \mathrm{E}$ Koc, ${ }^{2} \mathrm{C}$ Turkyilmaz, ${ }^{2} \mathrm{E}$ Onal, ${ }^{2} \mathrm{Y}$ Atalay. ${ }^{1}$ Pediatric Neurology, Gazi University Faculty of Medicine, Ankara, Turkey; ${ }^{2}$ Neonatology, Gazi University Faculty of Medicine, Ankara, Turkey; ${ }^{3}$ Pediatrics, Gazi University Faculty of Medicine, Ankara, Turkey

\subsection{6/archdischild-2014-307384.1045}

Background and aims We aimed to identify the neurodevelopmental and behaviour outcome of preterms (GA $<30 \mathrm{wks}$ ) at 8 years by age appropriate psychometric evaluations to see whether tests used at younger ages could predict worst outcomes at older ages in relation to some neonatal factors.

Method Along with neurologic examinations, 33 infants were prospectively evaluated at 3, 6, 12,18, 24 months of corrected age with Bayley Scales of Infant Development - II (BSID-II), at 3, 5 years with Stanford-Binet, at 8 years with WISC-R.

Results $72 \%$ of children had no (IQ $>85$ ), $24.3 \%$ had mild (IQ 74-84), 3\% had major (IQ $<70$, blindness) impairments. $24.2 \%$ had special education, 15.2\% ADHD, 6.1\% autism, 9.1\% learning/language, $6.1 \%$ anxiety disorders. The probability of neurodevelopmental test and IQ scores of VLBW infants $<1000 \mathrm{gr}$ being lower than healthy children at same age was 10.5 times higher (OR 4.7, 95\%, CI 0.92-24.5) at 8 years of age. Oxygen treatment $>30$ days adversely affected the scores up to 18th month (OR 2.1,\%95, CI 0.44-9.8). Babies having low scores of the18th month-cognitive and motor sub-test of BSID-II had 16 times higher probability of having low WISC-R total IQ scores at 8 years. $(p<0.05) .19$ children with sepsis at 8 years had lower performance and total IQ scores $(\mathrm{p}<0.05)$.

Conclusion Prolonged oxygen therapy and having and sepsis are significant factors affecting later IQ of VLBW infants. Lower BSID-II scores at 18 th month may predict future lower total IQ scores. Longitudional follow up and early intervention is of paramount importance.

\section{PO-0400 NEUROPROTECTIVE EFFECT OF PENTOXIFYLLINE IN RAT PUPS WITH HYPOXIC-ISCHAEMIC ENCEPHALOPATHY}

${ }^{1} \mathrm{H}$ Halis, ${ }^{1} \mathrm{~T}$ Gunes, ${ }^{2} \mathrm{~N}$ Liman, ${ }^{1} \mathrm{O}$ Bastug, ${ }^{3} \mathrm{~S}$ Bitiktas, ${ }^{3} \mathrm{~B}$ Tan, ${ }^{4} \mathrm{C}$ Süer. ${ }^{1}$ Neonatal Intensive Care Unit, Erciyes University Faculty of Medicine, Kayseri, Turkey; ${ }^{2}$ Histology and Embryology, Faculty of Veterinary Medicine, Kayseri, Turkey; ${ }^{3}$ Physiology, Erciyes University School of Medicine, Kayseri, Turkey; ${ }^{4}$ Physiology, Erciyes University Faculty of Medicine, Kayseri, Turkey 